\title{
Pressure Data Analysis and Multilayer Modeling of a Gas-Condansate Reservoir
}

\author{
Fatema Akter Happy, Mohammad Shahedul Hossain, Arifur Rahman
}

Department of Petroleum \& Mining Engineering, Shahjalal University of Science and Technology, Sylhet, Bangladesh

\begin{abstract}
Kailastila gas field located at Golapgonj, Sylhet is one of the largest gas fields in Bangladesh. It produces a high amount of condensate along with natural gas. For the high values of GOR, it may be treated as a wet gas at reservoir condition. Three main sand reservoirs are confirmed in this field (upper, middle \& lower).In this study, it has been shown that reservoir parameters of this gas field can be obtained for multilayered rectangular reservoir with formation cross-flow using pressure and their semi log derivative on a set of dimensionless type curve.The effects of the reservoir parameters such as permeability, skin, storage coefficient, and others such as reservoir areal extent and layering on the wellbore response, pressure are investigated.Shut in pressures are used in calculating permeability, skin factor, average reservoir pressure, wellbore storage effect and other reservoir properties. The direction of the formation cross flow is determined, first by the layer permeability and later by the skin factor.Finally, it is recommended to perform diagnostic analysis along with multilayer modeling to extract better results. Reservoir can also be considered as a multilayer cylindrical and can also use these models for other fields.
\end{abstract}

Keywords: Pressure derivative analysis, skin factor, wellbore storage, permeability, multilayer
This article is is licensed under a Creative Commons AttributionNonCommercial 4.0 International License.

Attribution-NonCommercial (CC BY-NC) license lets others remix, tweak, and build upon work non-commercially, and although the new works must also acknowledge \& be noncommercial.

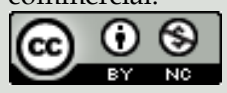

\section{How to Cite:}

Happy FA, Hossain MS and Rahman A. 2014. Pressure Data Analysis and Multilayer Modeling of a GasCondansate Reservoir Asia Pacific Journal of Energy and Environment, 1, 172-181.

Source of Support: Nil Conflict of Interest: Non declared

\section{INTRODUCTION}

Kailastila gas field is one of the largest gas producing fields in Bangladesh. The objectives of this study are to estimate reservoir properties by performing diagnostic analysis and to create multilayer model of Kailastila gas field.

A common practice for development of multilayer gas and gas condensate fields involves wells producing commingled fluids from several formations that comprise one production target. For example, in West Siberia, multilayer fields producing from two or five or more formations are included in the commingled production zone. Although this practice can be economical in that it decreases the number of wells per field, simultaneous production 
from several formations similar reservoir properties (thickness, permeability, porosity and initial gas saturation), in many cases it is necessary to include a formation with considerably different thickness and permeability values. Such a variance in reservoir properties can lead to uneven damage and rapid depletion of more permeable formations. In this case, a well shutdown is accomplished by gas cross flow between formations (Shandrygin etl, 2010).

In this study multilayer modeling is created for three layers by using Bourdet model. The direction of the formation cross flow is determined, first by the layer permeability and later by the skin factor.Well test data has often been interpreted based on an assumption that the reservoir is a homogeneous single layer. However, many reservoirs are found to be composed of a number of layers whose characteristics are different from each other. Wells in such reservoirs may produce from more than one layer (Bourdet etl, 1989). This kind of pressure behavior which indicates vertically heterogeneous system is not necessarily like that of a single layered system, and seldom reveals more than the average properties of the entire system. To identify the characteristics of the individual layers is important to extract better results.

\section{Gas Production From Multilayer Reservoir}

\section{Model Assumption}

Modeling is the process of history matching of pressure transient data based on a mathematical model. It is important to analyze the pressure transient data before modeling because it forces the analyst to think about the probable reservoir configurations and provides good estimates of reservoir parameters (Fekete, 2009). Multilayer modeling, a tool based on theoretical background, simulates the pressure responses in a multilayered well within a rectangular shaped reservoir with homogeneous characteristics in individual layer.

The model used here to describe multi-layer reservoir was developed by D. Bourdet. It is based on the following assumptions:

-The fluids flow horizontally each layer.

-The vertical flow between the three layers is instantaneously pseudo-steady state.

\section{Model Description}

Two different multilayered reservoir models have been proposed, depending on the presence or absence of interlayer cross flow. A multilayered reservoir is called a cross flow system if fluid can move between layers and a commingled system if layers communicate only through the wellbore.In this study, commingled system is used. This model simulates the transient flow in any number of independent layers commingled at the wellbore. Each layer is considered to have a rectangular geometry with an identical initial pressure $\left(p_{i}\right)$ to other layers as well as its own skin factor, reservoir properties, and outer boundary condition (Perk, 1989).

The reservoir with multi layers is characterized by its:

-net thickness

-porosity

-saturation

-pore compressibility

-horizontal permeability 
-vertical permeability

-skin

The main parameters that are involved in this model are:

-Total reservoir transmissivity

$\mathrm{kh}=\mathrm{k}_{1} \mathrm{~h}_{1}+\mathrm{k}_{2} \mathrm{~h}_{2}+\mathrm{k}_{3} \mathrm{~h}_{3}$

-The skin of each layer: $S_{1}, S_{2}, S_{3}$

-Total reservoir capacity, $\varphi c_{t}$

-Capacity contrast between three layers, $\omega$ (Bourdet etl, 1989).

In this study, It is attempted to match the semi log curve mainly, then derivative type curve and dimensionless type curve to get a good model match with reservoir parameters but it does not attempted to match the wellbore storage regime because the buildup shows some transients occurring while the was shut-in and the wellbore storage effect could not be captured analytically analysis.

\section{Pressure Derivative Analysis with Multilayer Modeling}

Several methods can be considered in testing a multilayer model. They do not all allow the individual characteristics of each layer to be determined. Each layer has been tested separately.

The values of parameter obtained during the analysis step provide a good starting point for an appropriately chosen model type. Parameters can then be optimized by automatic parameter estimation (APE). Before using the APE method, corrupted data should be removed from the data set to prevent the attempted match from invalid points (Fekete, 2009).

The pressure build-up test, type curve analysis, Dietz_MBH method and multilayer modeling are used to complete this study. Permeability and skin due to damage are estimated by build-up test of radial analysis by developing semi log and derivative type curves. These values of parameters are used as input parameters for Dietz_MBH method. The Dietz_MBH method gives the output values of reservoir areal extents and these areal extents again used as input parameters for Dietz_MBH method and finally the average reservoir pressure is estimated..Multilayer modeling is created by adding three layers. The properties of these three layers such as permeability, thickness, compressibility, viscosity, and capacity contrast $\omega$ and exchange term $\lambda$ are inserted. Then multilayer model is created.

Figure 1, 2, 3, 4, 5 and Figure 6 illustrates the multilayer model analysis results for the KTL-01, KTL-02 \& KTL-04 in graphical form. From Figure- 1, 3 \&5 it is seen that the modeled pressure line well matched with reservoir original pressure data points except slight deviation in the tail portion. Figure 2, 4 \& 6 of derivative type curves shows all three pressures, pressure derivative and dimensionless pressure derivative model curves near closely fitted with corresponding reservoir data points.

\section{Influence of Reservoir Properties on Production}

In this section I presented a brief discussion on parameters obtained from diagnostic analysis, vertical model analysis, and multilayer model analysis. From table 4, it is obtained that the total skin effect $(S)$ is negative for well KTL-01.For well KTL-02, total skin effect is positive. Total skin effect for well KTL-04 is positive and greater than KTL02.These total negative skin indicates the well can be either stimulated or damaged. Because all the skin components that contribute to the total skin are always non-negative 
(i.e. are zero or positive) except for skin due to damage $\left(S_{d}\right)$. The positive skin for KTL-02 and KTL-04 cannot give us clear information that it is damaged because the skin components have not been analyzed.

The average reservoir pressure, $\mathrm{P}_{\text {avg }}$ (3501.1.psia) for KTL-01 and $\mathrm{P}_{\mathrm{avg}}$ (3489.7) for KTL-04 from Dietz_MBH analysis in Table 7.1 and Table 7.3 are closer to initial reservoir pressure indicate that the reservoir is at its early stage of production. In case of KTL-02 the average reservoir pressure is greater than the initial reservoir pressure. This is due to either for error in data recording during test.

The areal extents show the reservoir is rectangular in shape which is consistent with assumption.

The estimated parameters are tabulated here from pressure semi log plots, pressure derivative type curve and dimensionless type curve. The resultant values of a specific parameter obtained from all analysis methods are same so they are not repeated.

Extrapolated pressure, $\mathrm{P}^{*}=3503.3$ psia for KTL-01, $\mathrm{P}^{*}=3222.1$ psia for KTL-02 and $\mathrm{P}^{*}=$ 3489.7 for KTL-04 are found for final shut in pressure 3499.29 psia,3221.1 psia and 3488.9 respectively.

A multilayered system with formation cross flow responds to the production in three progressive stages. It behaves like a commingled system at early time and like an equivalent homogeneous system at late time (the semi-log straight line in the pressure curve). Transition occurs in the intermediate stage. The direction of the cross flow is governed first by the permeability and next by the skin factors. The cross flow starts from the less permeable layer to the more permeable layer in the beginning and from the layer with greater skin to the layer with smaller skin later (Perk, 1989).

From multilayer modeling, it is obtained that the permeability of layer 1 is greater than layer 2 and the permeability of layer 2 is greater than layer 3 for KTL-01, KTL-02 and KTL04 .On the other hand the skin effect of layer 1 is smaller than layer 2 and layer 2 is smaller than layer 3.So the cross flow starts from layer 3 to layer 1 through layer 2.This time it behaves like a commingled system (Al-Mansoori, 2007).

Damage ratio refers that pressure drop due to skin is high. Recovery technique should be taken.

Flow efficiency indicates that the reservoir has fair flow capacity.

\section{ConcLusion}

A multilayered system with formation cross flow responds to the production in three progressive stages. It behaves like a commingled system at early time and like an equivalent homogeneous system at late time (the semi log straight line in the pressure curve). Transition occurs in the intermediate stage.The direction of the cross flow is governed first by the permeability's and next by the skin factors. The cross flow starts from the less permeable layer to the more permeable layer in the beginning and from the layer with greater skin to the layer with smaller skin later.From this study, it is obtained that the permeability of layer 1 is greater than layer 2 and the permeability of layer 2 is greater than layer 3 for KTL-01, KTL-02 and KTL-04. On the other hand the skin effect of layer 1 is smaller than layer 2 and layer 2 is smaller than layer 3.So the cross flow starts from layer 3 to layer 1 through layer 2. This time it behaves like a commingled system.According to the diagnostic analysis results, it is sighted that the analysis value of permeability of KTL-01, KTL-02 \& KTL-04 are $47.5327 \mathrm{md}, 690.8167 \mathrm{md}, 283.1997 \mathrm{md}$. It is clear that Kailastila is a good reservoir and have good permeability as well as good flow 
capacity. Finally, Multilayer modeling can be a good tool to estimate reservoir properties as it is not possible to acquire the whole reservoir characteristics by investigating only one layer. But if multilayer layer modeling is performed it is easy to characterize the whole reservoir.

\section{ACKNOWLEDGEMENT}

We are thankful to petrobangla for providing us the required data for analysis. We also want to thank the the Department of Petroleum and Mining Engineering, Shahjalal University of Science and Technology, Sylhet, Bangladesh, and all its staff members for providing us with the necessary education and computing resources throughout our work. Last, but not the least, thanks to our friends and family for their kind support.

\section{NOMENCLATURE}

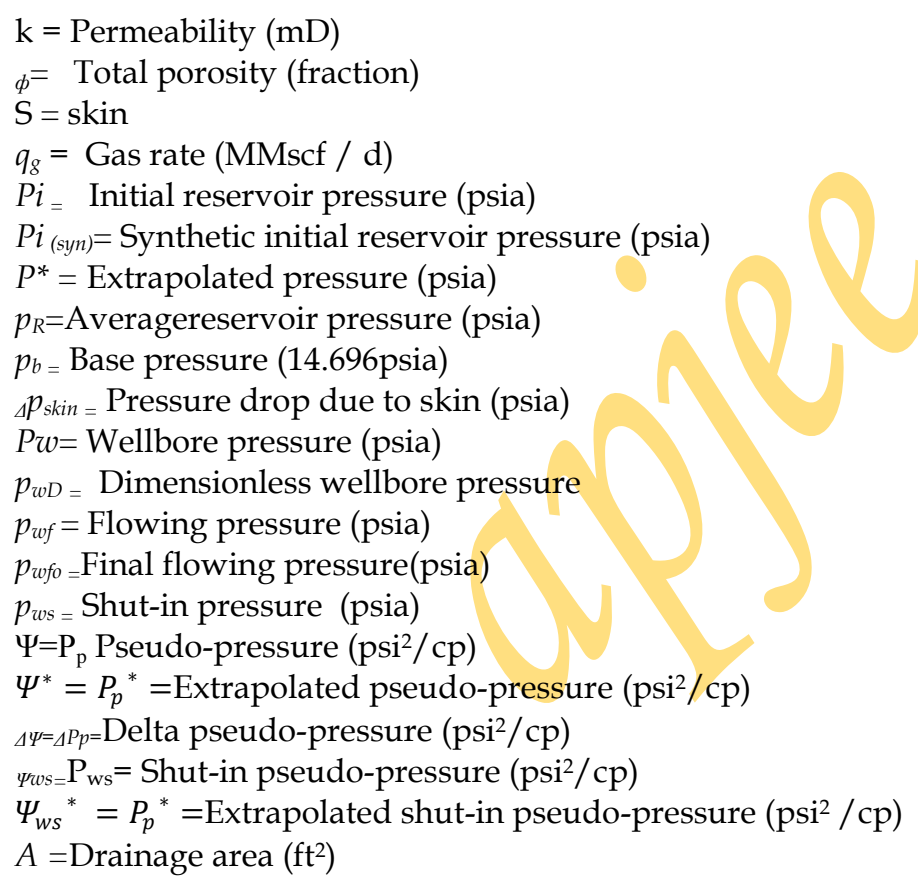

\section{REFERENCES}

A. Shandrygin, D. Rudenko, and D. Kuzmichev(2010), "Influence of the Multi-Layered Reservoir on the Production Dynamics of the Gas Condensate Well During Multi Rate Testing", SPE 138087 MS.

AL-MANSOORI wire line services, (2007).Pressure Transient Analysis Report, Bangladesh.

D. Bourdet, J.A. Ayoub, and Y.M. Pirard(1989), "Use of Pressure Derivative in Well-Test Interpretation", SPE Formation Evaluation.

Fekete Associates Inc., (2009), F.A.S.T Well Test ${ }^{T M}$,Alberta, Canada.

Perk, H. (1989), Well Test Analysis of a Multilayered Reservoir with Formation Cross flow, PhD thesis, Stanford University, California. 
Asia Pacific Journal of Energy and Environment, Volume 1, No 2 (2014)

Table 1: General input parameters for KTL-01. All values are taken from the report of AL MANSOORI Wireline Services.

\begin{tabular}{|l|c|l|}
\hline General Input Parameter & Values & Remarks \\
\hline Parameters & 4 & Provided by Client \\
\hline Well Radius (inches) & 65 & $\begin{array}{l}\text { Interval tested: 9652'-9655', 9658'-9664', } \\
9668^{\prime}-9722^{\prime}\end{array}$ \\
\hline Net Drained Thickness (ft) & 0.16 & Assumed value \\
\hline Effective Porosity (\%) & 0.59 & Reported value during the test \\
\hline Gas Gravity & 1000 & \\
\hline Primary Separator Pressure (Psia) & 70 & \\
\hline Primary Separator Temp ('F) & 0.142 & Provided by Client \\
\hline CO2 Component (mol \%) & Nill & Provided by Client \\
\hline H2S Component (mol \%) & N/A & Provided by Client \\
\hline N2 Component (mol \%) & 10000 & Assumed value \\
\hline Water Salinity (ppm) & 3515 & From the PTA \\
\hline Initial Reservoir Pressure (Psia) & 166.3 & From the Temperature Gauge \\
\hline Initial Reservoir Temp ('F) & N/A & Not relevant \\
\hline Rock Compressibility (psi-1) & 64 & Provided by Client \\
\hline Gas Saturation(\%) & 0.0196 & Calculated value \\
\hline Gas Viscosity( $\left.\mu_{\mathrm{g}}\right)$ & 0.856 & Calculated value \\
\hline Gas compressibility factor(z) & 36 & Provided by Client \\
\hline Connate water saturation $(\%)$ & \multicolumn{2}{|l}{} \\
\hline
\end{tabular}

Table 2: General input parameters for KTL-02.All values are taken from the report of AL MANSOORI Wire line Services.

\begin{tabular}{|l|c|l|}
\hline General Input Parameters & Values & Remarks \\
\hline Parameters & 3.5 & Provided by Client \\
\hline Well Radius (inches) & 40 & Interval tested: 7390'-7430' \\
\hline Net Drained Thickness (ft) & 0.16 & Assumed value \\
\hline Effective Porosity (\%) & 0.586 & Reported value during the test \\
\hline Gas Gravity & 1000 & \\
\hline Primary Separator Pressure (Psia) & 70 & \\
\hline Primary Separator Temp ('F) & 0.139 & Provided by Client \\
\hline CO2 Component (mol \%) & Nill & This value is not available \\
\hline H2S Component (mol \%) & N/A & This value is not available \\
\hline N2 Component (mol \%) & 10000 & Assumed value \\
\hline Water Salinity (ppm) & 3221 & From the PTA \\
\hline Initial Reservoir Pressure (Psia) & 145.11 & From the Temperature Gauge \\
\hline Initial Reservoir Temp ('F) & N/A & Not relevant \\
\hline Rock Compressibility (psi-1) & 85 & Provided by Client. \\
\hline Gas Saturation & 0.0192 & Calculated Value \\
\hline Gas Viscosity $\left(\mu_{\mathrm{g}}\right)$ & 0.884 & Calculated Value \\
\hline Gas compressibility factor(z) & 15 & Provided by Client. \\
\hline Connate water saturation $(\%)$ & & \\
\hline
\end{tabular}


Asia Pacific Journal of Energy and Environment, Volume 1, No 2 (2014)

Table 3: General input parameters for KTL-04.All values are taken from the report of AL

MANSOORI Wire line Services.

\begin{tabular}{|l|c|l|}
\hline General Input Parameters & Values & Remarks \\
\hline Parameters & 3.5 & Provided by Client \\
\hline Well Radius (inches) & 69 & Interval tested: 9610'-9673' and 9696'-9702' \\
\hline Net Drained Thickness (ft) & 0.1 & Assumed value \\
\hline Effective Porosity (\%) & 0.586 & Reported value during the test \\
\hline Gas Gravity & 1000 & \\
\hline Primary Separator Pressure (Psia) & 70 & \\
\hline Primary Separator Temp ('F) & 0.1432 & Provided by client \\
\hline CO2 Component (mol \%) & Nill & This value is not available \\
\hline H2S Component (mol \%) & $\mathrm{N} / \mathrm{A}$ & This value is not available \\
\hline N2 Component (mol \%) & 10000 & Assumed value \\
\hline Water Salinity (ppm) & 3491 & From the PTA \\
\hline Initial Reservoir Pressure (Psia) & 162.7 & From the Temperature Gauge \\
\hline Initial Reservoir Temp ('F) & $\mathrm{N} / \mathrm{A}$ & Not relevant \\
\hline Rock Compressibility (psi-1) & 64 & Provided by client \\
\hline Gas Saturation $(\%)$ & 0.0198 & Calculated Value \\
\hline Gas Viscosity $\left(\mu_{\mathrm{g}}\right)$ & 0.911 & Calculated Value \\
\hline Gas compressibility factor(z) & 36 & Provided by client \\
\hline Connate water saturation (\%) & &
\end{tabular}

Table 4: Multilayer model analysis value for KTL-01, KTL-02 \& KTL-04

\begin{tabular}{|l|l|l|l|l|l|l|l|l|l|}
\hline Well No. & \multicolumn{3}{|c|}{ KTL-01 } & \multicolumn{4}{c|}{ KTL-02 } & \multicolumn{4}{c|}{ KTL-04 } \\
\hline Parameters & $\begin{array}{l}\text { Layer 1 } \\
\text { Value }\end{array}$ & $\begin{array}{l}\text { Layer 2 } \\
\text { Value }\end{array}$ & $\begin{array}{l}\text { Layer 3 } \\
\text { Value }\end{array}$ & $\begin{array}{l}\text { Layer 1 } \\
\text { Value }\end{array}$ & $\begin{array}{l}\text { Layer 2 } \\
\text { Value }\end{array}$ & $\begin{array}{l}\text { Layer 3 } \\
\text { Value }\end{array}$ & $\begin{array}{l}\text { Layer 1 } \\
\text { Value }\end{array}$ & $\begin{array}{l}\text { Layer 2 } \\
\text { Value }\end{array}$ & $\begin{array}{l}\text { Layer 3 } \\
\text { Value }\end{array}$ \\
\hline $\mathrm{P}_{(\text {avg.) }}($ psia) $)$ & 3493.0 & 3493.0 & 3493.0 & 3221.3 & 3221.3 & 3221.3 & 3490 & 3490 & 3490 \\
\hline $\mathrm{P}^{*}(\mathrm{psia})$ & 3492.8 & 3492.8 & 3492.8 & 3219.9 & 3219.9 & 3219.9 & 3488.7 & 3488.7 & 3488.7 \\
\hline $\mathrm{P}_{(\text {syn) }}(\mathrm{psia})$ & 3493.6 & 3493.6 & 3493.6 & 3221.9 & 3221.9 & 3221.9 & 3490.7 & 3490.7 & 3490.7 \\
\hline $\mathrm{C}_{\mathrm{D}}$ & 165 & 165 & .165 & 23015.52 & 23015.52 & 23015.52 & 2074.818 & 2074.818 & 2074.818 \\
\hline $\mathrm{K}(\mathrm{md})$ & 43 & 46 & 43 & 610 & 600 & 605 & 110 & 100 & 90 \\
\hline $\mathrm{h}(\mathrm{ft})$ & 66 & 63 & 60 & 40 & 37 & 36 & 69 & 67 & 70 \\
\hline $\mathrm{Kh}(\mathrm{md} . \mathrm{ft})$ & 2838 & 2898 & 2640 & 24400 & 22200 & 21780 & 7590 & 6700 & 6300 \\
\hline $\mathrm{S}_{\mathrm{d}}$ & -3.311 & -2.50 & -3.010 & 11 & 14 & 16 & 3 & 4 & 5 \\
\hline$\omega$ & 0.1 & 0.08 & 0.09 & 0.1 & 0.6 & 0.9 & 0.1 & 0.8 & 0.9 \\
\hline$\lambda$ & $1.00 \mathrm{e}-06$ & $1.5 \mathrm{e}-06$ & $1.0 \mathrm{e}-06$ & $1.00 \mathrm{e}-06$ & $1.4 \mathrm{e}-06$ & $1.6 \mathrm{e}-06$ & $1.00 \mathrm{e}-06$ & $1.5 \mathrm{e}-06$ & $2.0 \mathrm{e}-06$ \\
\hline $\mathrm{X}_{\mathrm{e}}(\mathrm{ft})$ & 12700 & 12790 & 12810 & 11820 & 11823 & 11833 & 11822 & 11831 & 11836 \\
\hline $\mathrm{Y}_{\mathrm{e}}(\mathrm{ft})$ & 2180 & 2190 & 2200 & 2370 & 2374 & 2385 & 2370 & 2379 & 2387 \\
\hline $\mathrm{X}_{\mathrm{w}}(\mathrm{ft})$ & 6250 & 6325 & 6380 & 5910 & 5920 & 5927 & 5315 & 5327 & 5340 \\
\hline $\mathrm{Y}_{\mathrm{w}}(\mathrm{ft})$ & 1011 & 1030 & 1042 & 1185 & 1189 & 1194 & 1183 & 1189 & 1190 \\
\hline
\end{tabular}


Asia Pacific Journal of Energy and Environment, Volume 1, No 2 (2014)

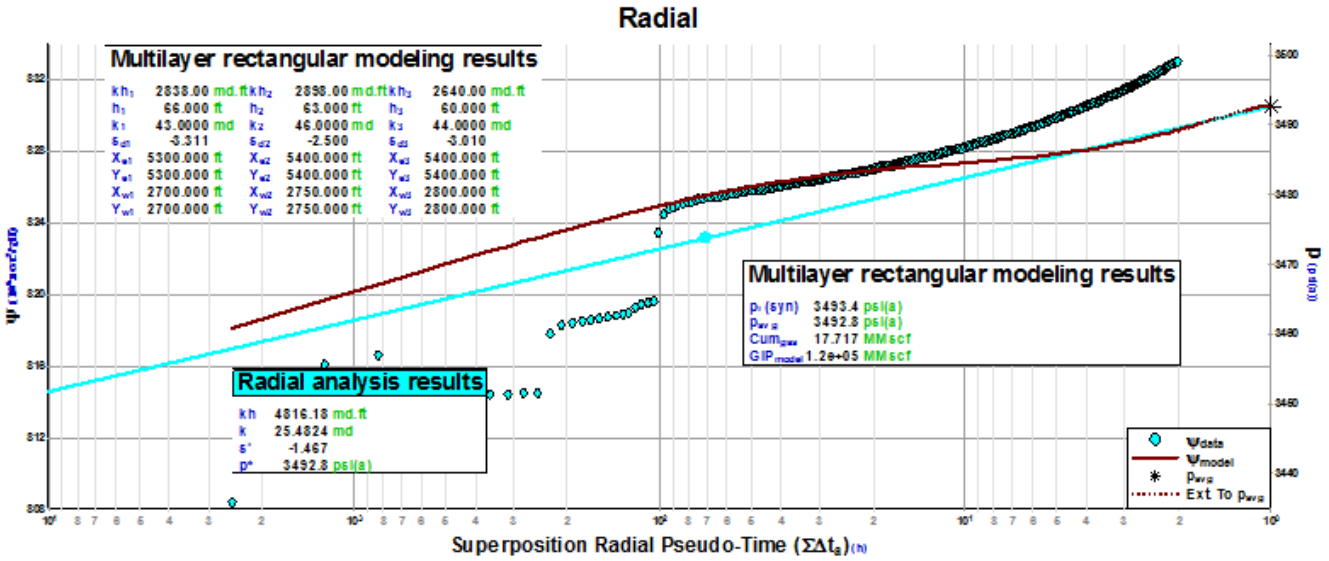

Figure-1: Semi log plot of multilayer model for pressure buildup test of KTL-01

\section{Derivative Typecurve}

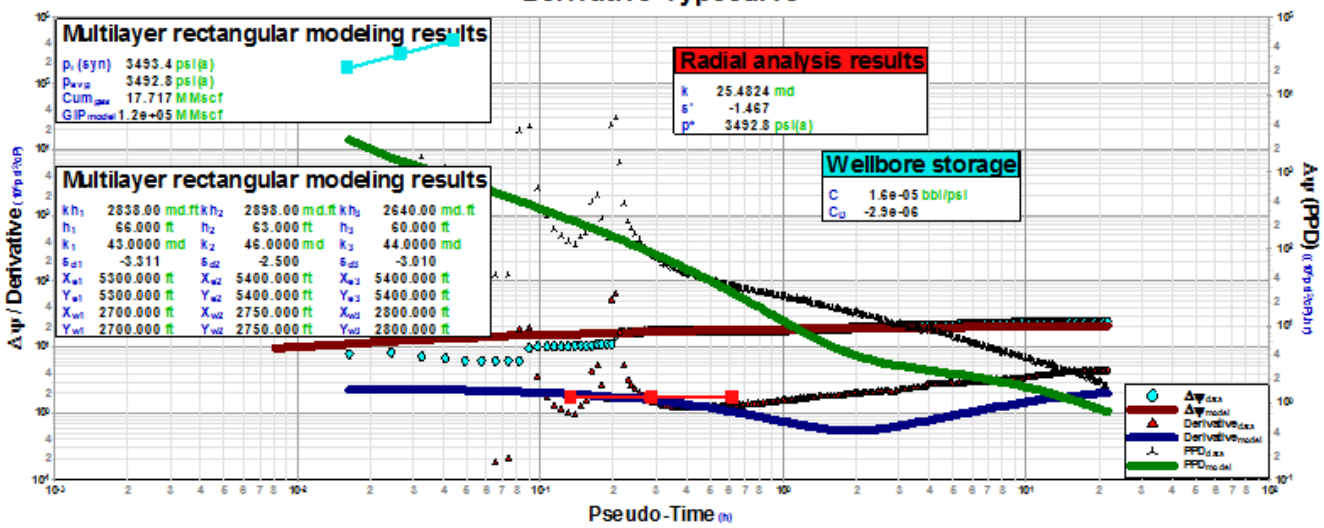

Figure-2: Pressure, Pressure derivative and Dimensionless pressure during buildup and multilayer model for KTL-01

Radial

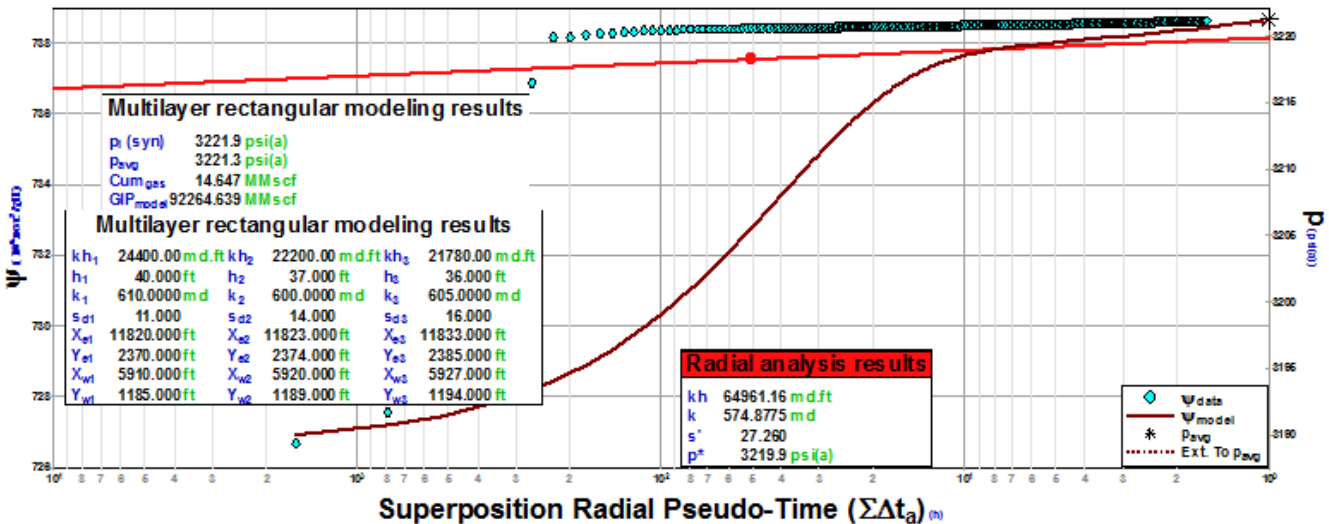

Figure-3: Semi log plot of multilayer model for pressure buildup test of KTL-02 
Asia Pacific Journal of Energy and Environment, Volume 1, No 2 (2014)

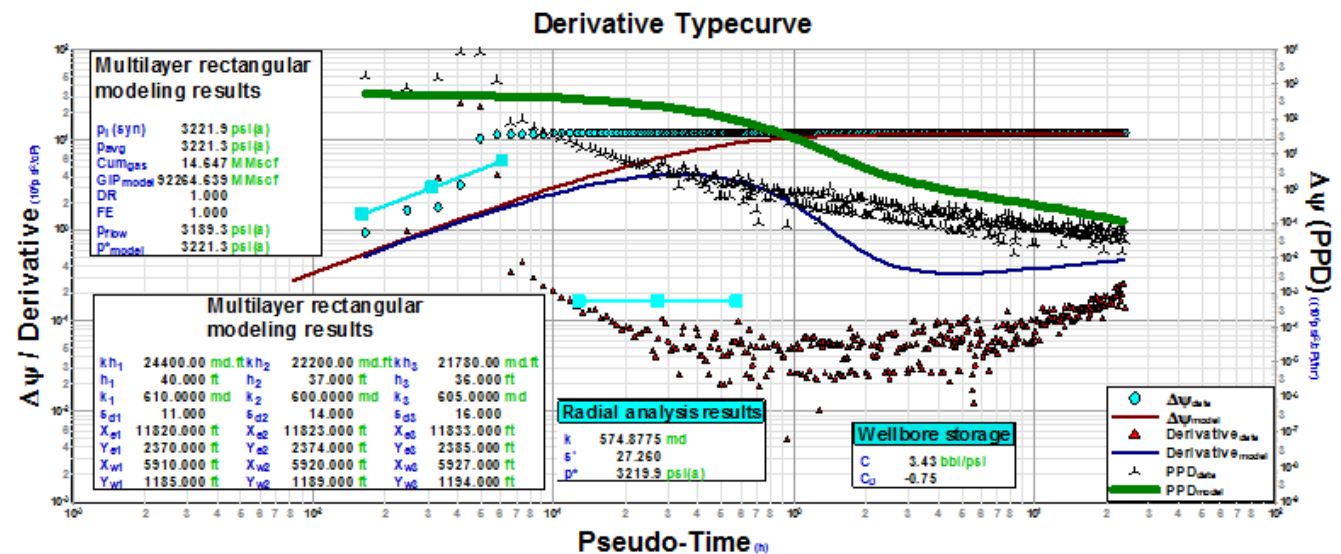

Figure-4: Pressure, Pressure derivative and Dimensionless pressure during buildup and multilayer model for KTL-02

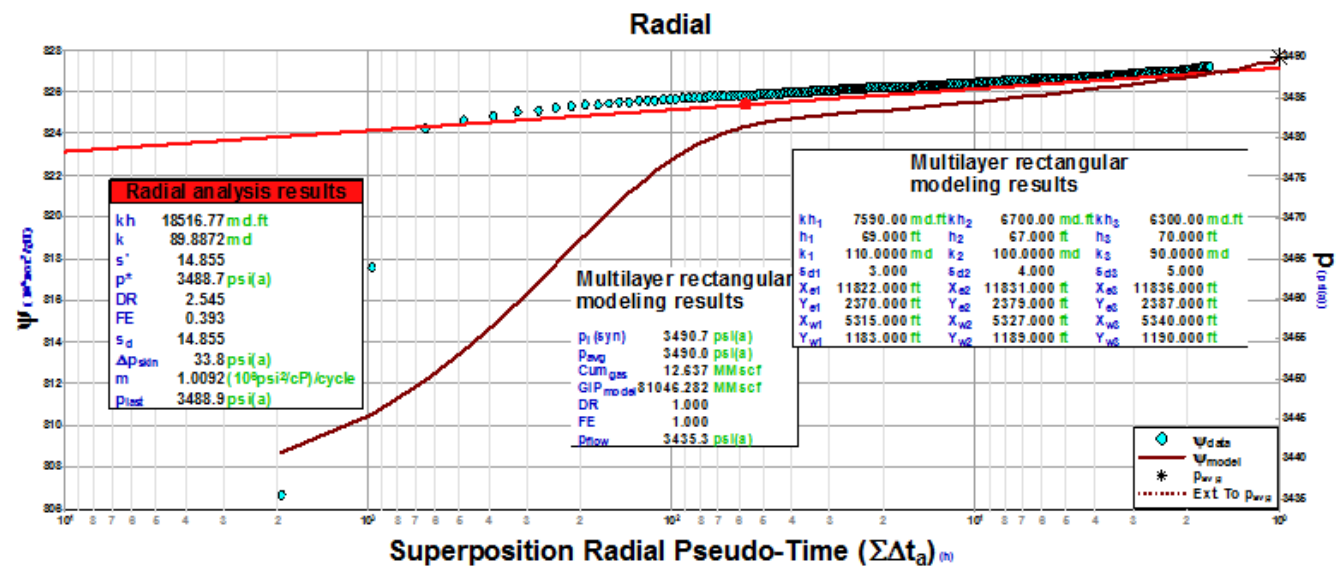

Figure-5: Semi log plot of multilayer model for pressure buildup test of KTL-04

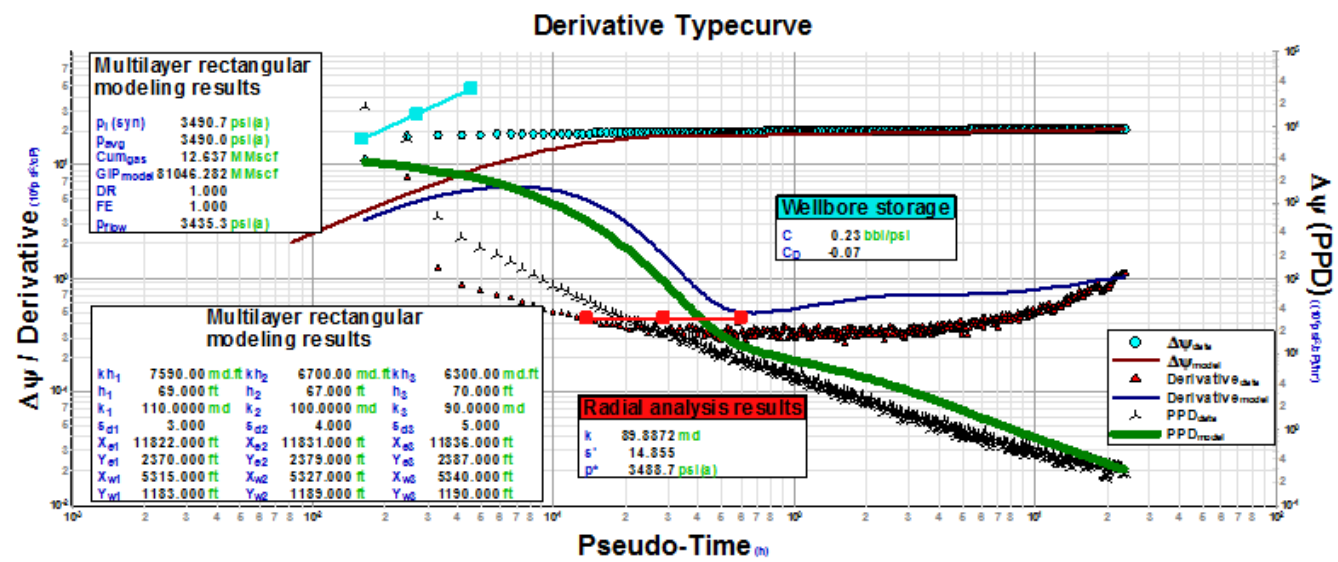

Figure-6: Pressure, Pressure derivative and Dimensionless pressure during buildup and multilayer model for KTL-04 
Asia Pacific Journal of Energy and Environment, Volume 1, No 2 (2014)

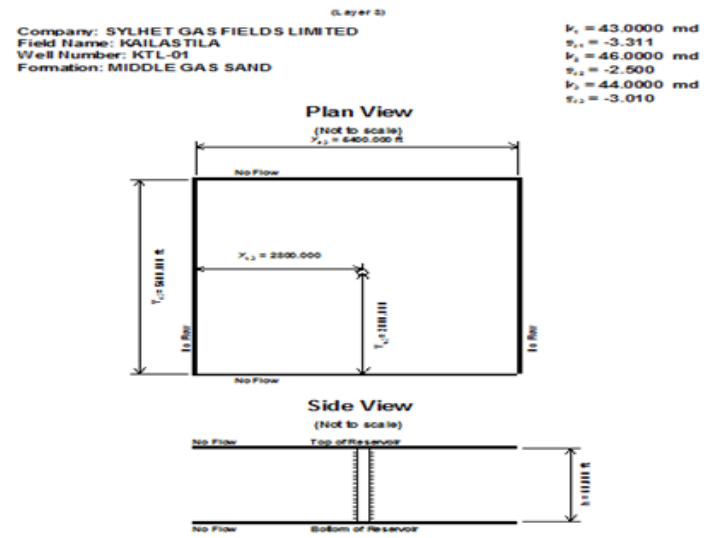

Figure 7: Plan view of layer of KTL-01

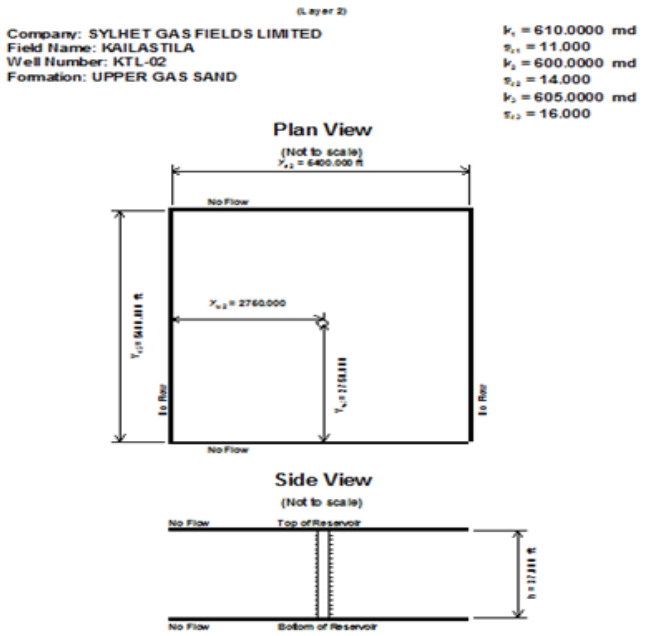

Figure 9: Plan view of layer of KTL-02

Multilayer Rect. 1

Comoanr: SYLHET GAS FIELDS LIMITED Field Name: KAILASTILA Well Number: KTL-02
Formation: UPPER GAS SAND

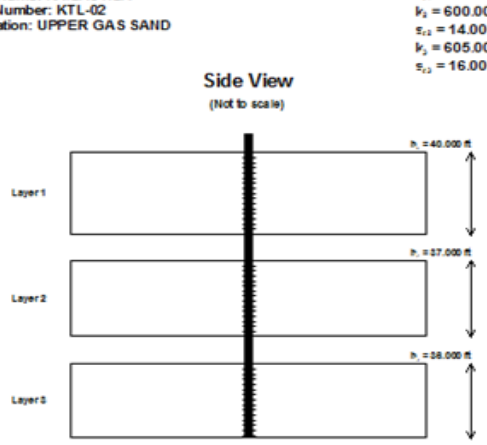

Figure 8: Side view of layers of KTL-02

Multilayer Rect. 1

Compary: SYHET GAS FIELDS LIMITED Field Name: KAILASTILA Well Number: KTL-04 Formation: LOWER GAS SAND

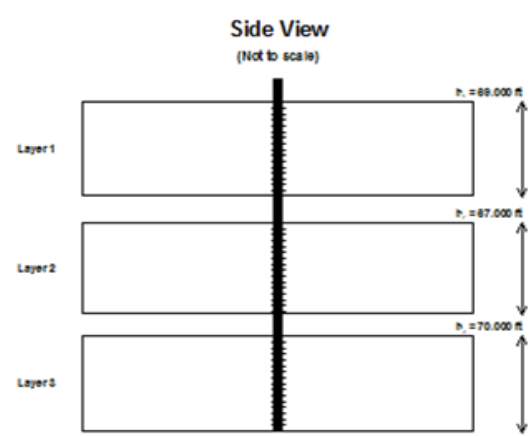

Figure 10: Side view of layers of KTL-04

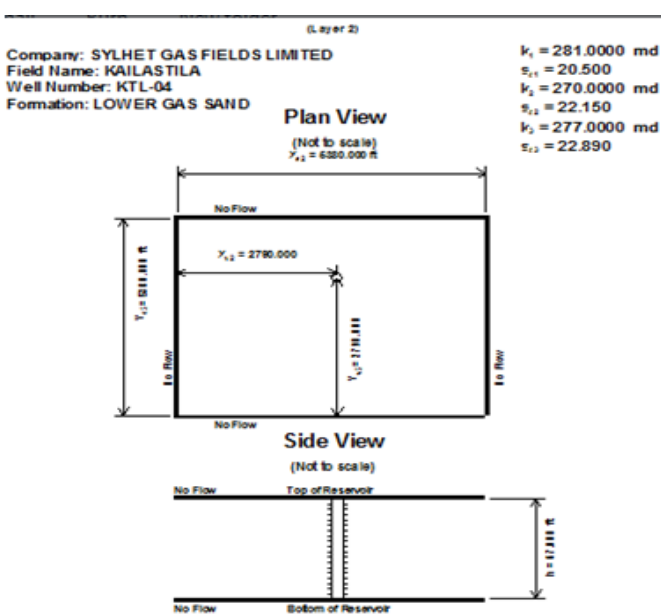

Figure 11: Plan view of layer of KTL-04 


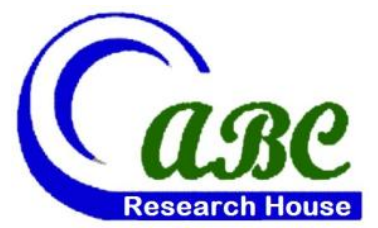

- Rd 4, Shyamoli, Dhaka-1207, Bangladesh

- Off Pantai Dalam, Kuala Lampur, Malaysia

- 3900 Woodhue Place, Alexandria, VA 22309, USA

www.abcreorg.weebly.com / www.abcjournals.net

Asian Business Consortium (ABC) is a multi-disciplinary research, training, publishing, digital library supporting and service house. Though founded in 2010 as the Business and Computing organization of Asia, it was reconstituted as the ABC in 2011. It has been working for creating and nurturing talents in USA, Malaysia and Bangladesh since its inception. As ABC is going global, it intends to open chapters in Australia, Germany, Japan, Pakistan, and other Asian countries in near future. The objectives of consortium are solely centered round the welfare and humane attitude of the founders who enthusiastically took up this noble cause and materialized it with a view to promote research and educational activities for the encouragement of scholars to develop their knowledge, to publish their analysis oriented scientific researches in international Journals, books, the task of organizing workshops, seminars, conferences, training, personality development programs and allied services.

In addition to research activities, ABC provides a good number of scholarships to the poor and meritorious students at various levels of education throughout the world. It plays an important role in the field of research by funding research projects and publishing the research papers. This consortium will unquestionably become the mouth-piece of the dark horses and unacknowledged scholar whose endowed and commendable contributions shall be provided an outlet keeping in mind the greater good of the larger society of the world.

$\mathrm{ABC}$ runs the following international referred journals for creating a platform to share the thoughts of professionals, scholars and academicians throughout the world.

\section{ABC Publications (ABC Journals)}

- Asian Accounting and Auditing Advancement (4A Journal)

- Asian Business Review (ABR)

- Asian Journal of Applied Sciences and Engineering (AJASE)

- Global Disclosure of Economics and Business (GDEB)

- $\quad$ ABC Journal of Advanced Research (ABC-JAR)

- International Journal of Reciprocal Symmetry and Theoretical Physics (IJRSTP)

- American Journal of Trade and Policy (AJTP)

- Asian Journal of Humanity, Art and Literature (AJHAL)

- Malaysian Journal of Medical and Biological Research (MJMBR)

- Asia Pacific Journal of Energy and Environment (APJEE)

- $\quad$ Engineering International (EI)

- $\quad$ ABC Research Alert (Online)

Each journal home page provides specific information for potential authors and subscribers. Open access policy, the quick review process, rich editorial boards and quality publications have already made $A B C$ Journals unique. ABC Journals are published under the direct supervisions of renowned academicians of the world.

Collaboration in Conference: $\mathrm{ABC}$ considers high-quality conference papers for publication. Please contact us for detailed information.

Collaboration in Publishing: If you like to start writing a book, propose a new journal or advertise in $\mathrm{ABC}$ journals, please feel free to contact us. 